www.jmscr.igmpublication.org

Impact Factor 5.84

Index Copernicus Value: 71.58

ISSN (e)-2347-176x ISSN (p) 2455-0450

crossref DOI: _https://dx.doi.org/10.18535/jmscr/v5i11.197

Journal Of Medical Science And Clinical Research

\title{
Study on Acute Illness Observation Scale in Children with Respiratory Illness with Radiological Correlation
}

\author{
Authors
}

\section{Sivakami $\mathbf{M}^{1}$, Balachandran.C.S. ${ }^{2}$, Chidambaranathan.S. ${ }^{3}$}

${ }^{* 1}$ Post Graduate, Department of Paeditrics, RMMCH, Chidambaram-608002, Tamilnadu, India

${ }^{2}$ Professor, Department of Paeditrics, RMMCH, Chidambaram-608002, Tamilnadu, India

${ }^{3}$ Associate Professor, Department of Paeditrics, RMMCH, Chidambaram-608002, Tamilnadu, India

\begin{abstract}
Background: Acute respiratory illness (ARI) is the most common cause of preventable mortality in under five aged children. For the early recognition of severity and prompt treatment of ARI Acute illness observation scale (AIOS) an illness severity scale developed by P.L.McCarthy on the basis of simple observation was used in the current study. This score is a sensitive tool to identify severity of illness. So this score was used in the study to correlate with radiological abnormalities in children with ARI.

Methodology: The current study is a descriptive epidemiological study conducted in 60 children in the age group of 2-59 months with acute respiratory illness. AIOS score was calculated for every child and $x$-ray was taken on the day of admission and the results were correlated.

Results: On the basis of the AIOS score the children were stratified. The relationship between AIOS score and the $x$-ray abnormalities were studied. There were 7 children who scored 10 with no signs of respiratory distress. In the 12 children who scored 11-15 there was mild to moderate distress and there were 41 children with severe distress who scored $>16$. In the $x$-ray, radiological abnormalities like hyperinflation (Bronchiolitis) was present in 16 children of which 19\% of children scored $11-15$ and $75 \%$ of the children scored >16. Radiological abnormalities suggestive of pneumonia were present in 33 patients of which 24\% of them were in 11-15 group and 66\% of them were present in >16 as per AIOS score. On statistical analysis it was found that AIOS score is significant in predicting abnormal radiological findings ( $p$ value $=0.002$ ) in ARI in under five aged children.

Conclusion: AIOS scoring is useful in predicting abnormal $x$-ray findings in respiratory illness in 2-59 months old children.
\end{abstract}

\section{Introduction}

Paediatric respiratory disease remains an important cause of morbidity in both the developing and the developed world. ${ }^{1}$ It is the most common reason parents give for taking their children to see the physician and for attending a emergency department with a medical problem ${ }^{3}$. In India, Acute respiratory infections accounts for $30-60 \%$ of outpatient visits to hospital and $20-30 \%$ of them need admission in hospital ${ }^{2}$. ARI is the leading cause of acute illness worldwide and the most important cause of mortality of under five year aged children, which accounts for about 2 million deaths each year ${ }^{4}$.

Prompt understanding of well being of a child with ARI is essential for triage, early referral, hospitilization and initiating treatment interventions in developing countries. ${ }^{5}$ For this purpose the Acute illness observation 
scale(AIOS) an illness severity scale developed by P.L.McCarthy on the basis of simple observations made in the emergency department was used in this study. The score thus obtained in the cases of ARI was correlated with radiological abnormalities and the results were analysed.

\section{Materials and methods}

The current study was conducted in Raja Muthiah Medical College and Hospital (RMMCH), Annamalai University Chidambaram, Tamilnadu after getting ethical committee clearance. The study period was 18 months.

Table 1: AIOS score: composition and score description

\begin{tabular}{|l|c|c|c|}
\hline Variables & Score =1 & Score=3 & Score=5 \\
\hline Quality of Cry & $\begin{array}{c}\text { Strong cry with normal } \\
\text { tone or contented and not } \\
\text { crying }\end{array}$ & Whimpering or sobbing & $\begin{array}{c}\text { Weak cry/ moaning, or } \\
\text { high-pitched cry }\end{array}$ \\
\hline $\begin{array}{l}\text { Reaction } \\
\text { Stimulation to parent }\end{array}$ & $\begin{array}{c}\text { Cries briefly and stops, or } \\
\text { is content and not crying }\end{array}$ & Cries on and off & $\begin{array}{c}\text { Cries continuously or } \\
\text { responds hardly }\end{array}$ \\
\hline State Variation & $\begin{array}{c}\text { when awake, stays awake, } \\
\text { or if stimulated while } \\
\text { sleeping, awakens quickly }\end{array}$ & $\begin{array}{c}\text { Closes eyes for short period } \\
\text { when awake, or awakens } \\
\text { when stimulated for long time }\end{array}$ & $\begin{array}{c}\text { Fast asleep or not } \\
\text { arousable }\end{array}$ \\
\hline Color & $\begin{array}{c}\text { Pink } \\
\text { Pale extremities /acrocyanosis }\end{array}$ & $\begin{array}{c}\text { Pale/ cyanotic/, mottled } \\
\text { /ashen }\end{array}$ \\
\hline $\begin{array}{l}\text { Hydration } \\
\text { Response to social } \\
\text { overtures }\end{array}$ & $\begin{array}{c}\text { Normal skin and eyes and } \\
\text { moist mucous membranes }\end{array}$ & $\begin{array}{c}\text { Normal skin and eyes, mouth } \\
\text { slightly dry }\end{array}$ & $\begin{array}{c}\text { Poor recoiling of skin, } \\
\text { mucous membranes dry } \\
\text { and/or eyes sunken }\end{array}$ \\
\hline
\end{tabular}

\section{Inclusion criteria}

Children in the age group of 2 months -59 months with fever less than 3 days, with cough or difficult breathing with any of the following: Fast breathing, chest in drawing, stridor in calm child, grunting, lethargy, convulsions, inability to drink.

\section{Exclusion criteria}

Illness duration >2 weeks, respiratory distress with prominent wheezing, upper respiratory infections with less severe respiratory symptoms, ex; acute otitis media, acute pharyngitis etc.,

\section{Results}

The sixty children who fit in the inclusion criteria were enrolled in the study and scored according to acute illness observation scale. In those children it was observed that $70 \%$ of children with respiratory illness scored abnormally (AIOS >10) at initial evaluation. The mean score for AIOS on Day 1 was around 18. Based on the score the children were grouped and correlated with x-ray abnormalities. There were 7 children who scored 10 and showed no clinical features of respiratory distress. In the 12 children who scored 11-15 there was mild to moderate respiratory distress and there were 41 children with severe respiratory distress who scored $>16$.

Among the 60 children $10 \%$ of the children had normal $\mathrm{x}$-rays. Hyperinflation pertinent to bronchiolitis was seen in 16 children

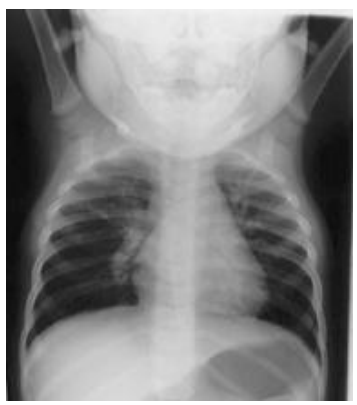

Image: Chest x-ray AP view: Hyperinflation in a case of Bronchiolitis

End point consolidation (include dense opacity that may be a fluffy consolidation) 
suggestive of lobar pneumonia was present in 18 patients $(30 \%)$.

Non end point infiltrates defined as linear and patchy densities with peribronchial thickening and many areas of atelectasis pertinent to bronchopneumonia was seen in 15 patients $(25 \%)$.

The other radiological abnormalities which were rare in the study were steeple sign $(3.3 \%)$, shock lung $(3.3 \%)$ and pleural effusion $(1.6 \%)$.

Table 2: X-ray findings

\begin{tabular}{|l|c|c|}
\hline & No. of patients & Percentage \\
\hline Normal study & 6 & 10 \\
\hline Hyperinflation & 16 & 26 \\
\hline End point infiltrates & 18 & 30 \\
\hline Non end point infiltrates & 15 & 25 \\
\hline Steeple sign & 2 & 3.3 \\
\hline Shock lung & 2 & 3.3 \\
\hline Pleural effusion & 1 & 1.6 \\
\hline Total & 60 & 100.0 \\
\hline
\end{tabular}

\section{Comparison of AIOS score and radiological abnormalities}

Hyperinflation (Bronchiolitis) was present in 16 children of which 3 (19\%) scored 11-15, and 12 $(75 \%)$ of the patients were in $>16$ group. Radiological abnormalities suggestive of pneumonia was seen in 33 patients of which 8 children (24\%) were in 11-15 group and $22(66 \%)$ scored $>16$ of AIOS score. There was noteworthy difference in the frequency of $x$-ray abnormalities between children who scored $<10$ and children who scored $>16$.

Table 3: Comparison of AIOS score and radiological findings

\begin{tabular}{|l|l|l|l|l|}
\hline & \multicolumn{3}{l}{ AIOS Level } & \multirow{2}{*}{ Total } \\
\hline X-ray & $\mathbf{1 0}$ & $\mathbf{1 1 - 1 5}$ & $\mathbf{1 6}$ & \\
\hline Normal study & 3 & 2 & 1 & 6 \\
\hline Hyperinflation & 1 & 3 & 12 & 16 \\
\hline End point infiltrates & 3 & 5 & 10 & 18 \\
\hline Non end point infiltrates & 0 & 3 & 12 & 15 \\
\hline Steeple sign & 0 & 0 & 2 & 2 \\
\hline Shock lung & 0 & 0 & 2 & 2 \\
\hline Pleural effusion & 0 & 0 & 1 & 1 \\
\hline Total & 7 & 12 & 41 & 60 \\
\hline
\end{tabular}

The other radiological abnormalities of steeple sign (Acute laryngo tracheo bronchitis), shock lung (ARDS), pleural effusion fell only in the $>16$ group.

The significance of AIOS score in predicing abnormal x-rays in ARI was analysed and was found to be statistically significant $(\mathrm{p}$ value $=$ $0.002)$.

\section{Discussion}

McCarthy PL et al in 1982 conducted a study to determine if observational assessment performed in a systematic manner adds to the effectiveness of the method of traditional history taking and physical examination in identifying serious illness in febrile children. To determine the sensitivity of the combined evaluation, he sequentially evaluated children of less than 24 months of age 
who presented with fever. ${ }^{6}$ This study showed that combination of AIOS scoring, history, and physical examination had a higher sensitivity and correlation for serious illness than did the traditional history and physical examination alone. Three children who had serious illness but showed no abnormalities on history and physical examination, were identified only by the use of AIOS.

This AIOS scoring system was studied by Bhavneet Barathi et al for assessing its usefulness in managing severe childhood pneumonia ${ }^{5}$ in 2-59 months.

Akash Bang et al and Prerena et al used this score for prediction of bacteremia in children aged $<36$ months with fever ${ }^{7,8}$.

Murali B.H et al compared AIOS score with IMCI and studied its sensitivity and specificity in prognosticating children with pneumonia in the age group of 2 to 59 months ${ }^{3}$.

In the current study AIOS score was correlated with radiological abnormalities in acute respiratory illness in 2-59 months. In the x-ray abnormalities the most common were end point infiltrates $(30 \%)$, hyperinflation $(26 \%)$ and non end point infiltrates (25\%). It was found that in the cases of hyperinflation (bronchiolitis) $75 \%$ of the findings were in children who scored $>16$. Likewise $55 \%$ of end point infiltrates (lobar pneumonia) and $80 \%$ of non end point infiltrates (bronchopneumonia) were in the patients who scored $>16$. That is the frequency of abnormal radiological findings were more if they scored $>16$ of AIOS score in a acute respiratory infections. This correlation was found to be significant $(\mathrm{p}$ value $=0.002)$

Similar observation was noticed in Murali B.H. et $\mathrm{al}^{3}$ study were when the AIOS score was $<10$ in cases of community acquired pneumonia $77.5 \%$ of $\mathrm{x}$-rays were normal

\section{Conclusion}

Acute illness observation scale is a useful tool in predicting abnormal radiological findings in children from 2-59 months with acute severe respiratory illness.

\section{References}

1. Mathew, et al., Acute Respiratory infection and Pneumonia in India:A systematic Review Indian Pediatrics Vol48-March 17, 2011.

2. Vinod K.Ramani et al, Acute respiratory infections among Under five age group children at urban slums of Gulbarga City: A Longitudinal Study, Journal of Clinical and Diagnostic Research 2016 May.

3. Murali B.H, Lingaraju Mulage, AIOS v/s IMNCI in community acquired pneumonia. Journal of Evolution of Medical and Dental Sciences2014; Vol. 3 Issue13, March31.

4. Nadia Montasser, et al Assessment and Classification of Acute Respiratory infections, British Journal of Medicine and Medical Research2 (2):216-227, 2012.

5. Bhavneet Bharti et al AIOS in managing severe childhood pneumonia Indian Journal of Pediatrics Volume 74-January, 2007.

6. Mc Carthy PL JekelJF, Stashwick CA,Spirsel SZ, Dolan TF, Sharpe MR et al. Further definition of history and observation variables in assessing febrile children. Pediatrics 1981; 67:687-93.

7. Akash Bang et al Yale observation Scale for Predicion of Bacteremia in Febrile children; Indian Journal of paediatrics, Vol76-June, 2009.

8. Prerana et al; Efficacy of Yale observation scale to detect serious bacterial infection in febrile children aged one to 36 months JPAHS. 2014Dec; 1(2): 23-26 